\title{
High-Pressure Liquid Chromatographic Separation of a Mixture of Corticosteroids, Androgens, and Progestins ${ }^{1}$
}

\author{
FORE-LIEN HUANG, FERNG-CHUN KE, JIUAN-JIUAN HWANG, \\ AND TUNG-BIN $\mathrm{LO}^{2}$ \\ Institute of Biological Chemistry, Academia Sinica and Institute of Biochemical Sciences, \\ National Taiwan University, Taipei, Taiwan
}

Received April 7, 1983

Fifteen steroids including corticosteroids, androgens, progestins, and their derivatives were completely separated by reverse-phase high-pressure liquid chromatography on a ChemcoPak 7 ODS-H column in $50 \mathrm{~min}$. The elution procedures were first with water:methanol:acetonitrile:isopropanol 55:32:6.5:7.5 (v/v) for $15 \mathrm{~min}$ and followed with a linear gradient elution for 35 min from 0 to $80 \%$ of water:methanol:n-butanol 40:40:20 $(v / v)$. The applicability of this method was successfully demonstrated in the analyses of the biological samples of carp plasma, testis, and head kidney.

In mammals, $11 \beta$-hydroxylase is found in adrenal gland but not in normal testis $(1,2)$; however, this enzyme is present both in fish testis and head kidney (3-5). Because of the presence of this enzyme in fish testis, the composition of testicular steroids becomes more complicated than those of mammals. Besides androgens, fish testis contains steroids like cortisone, cortisol, $11 \beta$-hydroxy- and 11-ketoandrogen, and $11 \beta$-hydroxy- and 11-ketoprogesterone. For further studies of steroidogenesis in testis and head kidney as well as function of gonadotropins in fish, a convenient analytical method with high resolution and sensitivity should be developed. In the past, analyses of steroid hormones have mostly depended on paper partition chromatography, thin-layer chromatography, and gas chromatography. Later, O'Hare et al. (6) had developed several high-pressure liquid chromatography (HPLC) systems for

\footnotetext{
${ }^{1}$ Dedicated to $\mathrm{Dr}$. Choh $\mathrm{HaO} \mathrm{Li}$ on the occasion of his 70th birthday.

${ }^{2}$ To whom all correspondence should be addressed: Institute of Biological Chemistry, Academia Sinica, P.O. Box 23-106, Taipei, Taiwan.
}

analysis of steroids secreted from cultured human adrenal and testis cells. In their systems, separation of different classes of steroids (e.g., corticosteroids and androgens) should be made by different solvent systems. Furthermore, some steroids cannot be separated completely by their systems. Recently a HPLC method which could separate 15 steroids including corticosteroids, androgens, and progestins (limited only $\alpha, \beta$-unsaturated 3-ketosteroids) by single run was developed in our laboratory. This paper presents our newly developed method and its application in steroid analyses of plasma, testis, and head kidney of carp.

\section{MATERIALS AND METHODS}

Chemicals. Organic solvents used were LC grade from Alps Chemical Company, Taiwan. The authentic steroids were from Sigma (St. Louis, Missouri) and the radioactive steroids were from the Radiochemical Center (Amersham, England). The trivial names and abbreviations of steroids used are listed in Table I.

Chromatography. The HPLC system used throughout this study is composed of a Tracor 951 LC pump (Tex.), a Rheodyne 7152 sample injector (Calif.), a Waters Associate Model 440 absorbance detector 
TABLE I

Trivial Names and AbBreviations

\begin{tabular}{lll}
\hline \multicolumn{1}{c}{ Trivial name } & Abbreviation & \multicolumn{1}{c}{ Chemical name } \\
\hline Adrenosterone & KA & Androst-4-ene-3,11,17-trione \\
Aldosterone & ALDO & $11 \beta, 21$-Dihydroxy-18-alpregn-4-ene-3,20-dione \\
Androstenedione & A & Androst-4-ene-3,17-dione \\
Corticosterone & $\mathrm{B}$ & $11 \beta, 21$-Dihydroxypregn-4-ene-3,20-dione \\
Cortisol & $\mathrm{F}$ & $11 \beta, 17 \alpha, 21$-Trihydroxypregn-4-ene-3,20-dione \\
Cortisone & $\mathrm{E}$ & $17 \alpha, 21$-Dihydroxypregn-4-ene-3,11,20-trione \\
$11-$-Deoxycortisol & $11-\mathrm{DOF}$ & $17 \alpha-21$-Dihydroxypregn-4-ene-3,20-dione \\
$11 \beta$-Hydroxyandrostenedione & OHA & $11 \beta$-Hydroxyandrost-4-ene-3,17-dione \\
$11 \beta$-Hydroxyprogesterone & $11-\mathrm{OHP}$ & $11 \beta$-Hydroxypregn-4-ene-3-one \\
$17 \alpha$-Hydroxyprogesterone & $17-\mathrm{OHP}$ & $17 \alpha$-Hydroxypregn-4-ene-3-one \\
$11 \beta$-hydroxytestosterone & OHT & $11 \beta, 17 \beta$-Dihydroxyandrost-4-ene-3-one \\
$11-$ Ketoprogesterone & KP & Pregn-4-ene-3,11,20-trione \\
11 -Ketotestosterone & $\mathrm{KT}$ & $17 \beta$-Hydroxyandrost-4-ene-3,11-dione \\
Progesterone & $\mathrm{P}$ & Pregn-4-ene-3-one \\
Testosterone & $\mathrm{T}$ & $17 \beta$-Hydroxyandrost-4-ene-3-one \\
\hline
\end{tabular}

(Mass.), an Eldex Chromat-A-Trol Model II solvent programmer (Calif.), a Shimadzu U-135 recorder (Kyoto, Japan), and a ChemcoPak 7 ODS-H column $(4.6 \times 250 \mathrm{~mm})$ (Osaka, Japan). The elution procedures were first performed by an isocratic elution with solvent A (water:methanol:acetonitrile:isopropanol 55:32:6.5:7.5, v/v) for $15 \mathrm{~min}$ then by a linear gradient elution built up to $80 \%$ solvent $B$ (water:methanol:nbutanol 40:40:20, v/v) within $35 \mathrm{~min}$.

Quantification of each steroid was based on peak area calculated as peak height $(\mathrm{cm}) \times$ peak width at half peak height $(\mathrm{cm})$. The standard steroid solution was prepared by dissolving authentic steroids in methanol $(20 \mu \mathrm{g} / \mathrm{ml})$. The regression equations of the quantity of authentic steroids (in the range of 25 to $400 \mathrm{ng}$ ) injected and the peak area monitored of the 15 authentic steroids are listed in Table II. These equations were used to estimate the quantity of the corresponding steroids present in unknown samples. For identification of the steroids present in unknown samples, cochromatography with authentic steroids was performed.

Sample preparation. The male carp (Cyprinus carpio L) was used throughout this study. No hormone was administered except one experiment in which carp gonadotropin (cGTH, ${ }^{3} 0.5 \mu \mathrm{g} / \mathrm{g}$ body weight) was injected to fish at the base of pectoral fin for testicular steroid analysis. The preparation of cGTH was the same as that previously described (7).

Before bleeding, the fish was stunned with a wooden hammer on the head region. Blood was drained from the cut end of caudal peduncle into a heparinized

\footnotetext{
${ }^{3}$ Abbreviation used: cGTH, carp gonadotropin.
}

tube. The plasma was separated by centrifugation. Plasma from several fishes were pooled and was extracted with $10 \mathrm{vol}(\mathrm{v} / \mathrm{v})$ of ether twice. The ether phase was evaporated to dryness under reduced pressure. The residue was redissolved in $10 \mathrm{ml}$ dichloromethane, and washed with $2 \mathrm{ml}$ each of water, 0.1 $\mathrm{N} \mathrm{NaOH}$ and $0.1 \mathrm{~N}$ acetic acid twice successively. The

\section{TABLE II}

The Regression Equations of The Quantity of Steroid InJected and the Peak Area Monitored of 15 Authentic Steroids

\begin{tabular}{lcc}
\hline Steroid & \multicolumn{1}{c}{ Equation } & $r^{c}$ \\
\hline KA & $Y^{a}=-0.01891+0.004366 X^{b}$ & 0.99938 \\
ALDO & $Y=-0.00677+0.004014 X$ & 0.99995 \\
A & $Y=0.00372+0.004867 X$ & 1.00000 \\
B & $Y=-0.01847+0.004286 X$ & 0.99983 \\
F & $Y=-0.00180+0.003975 X$ & 0.99994 \\
E & $Y=-0.02269+0.004431 X$ & 0.99937 \\
11-DOF & $Y=-0.00347+0.004651 X$ & 0.99940 \\
OHA & $Y=-0.02303+0.005332 X$ & 0.99936 \\
11-OHP & $Y=0.00657+0.004177 X$ & 0.99976 \\
17-OHP & $Y=-0.01576+0.004116 X$ & 0.99942 \\
OHT & $Y=-0.00842+0.005440 X$ & 0.99998 \\
KP & $Y=-0.00013+0.003917 X$ & 0.99996 \\
KT & $Y=0.00571+0.003490 X$ & 0.99988 \\
P & $Y=-0.04829+0.004608 X$ & 0.99873 \\
T & $Y=-0.00266+0.004177 X$ & 0.99972 \\
\hline
\end{tabular}

a The peak area $\left(\mathrm{cm}^{2}\right)$.

${ }^{b}$ The quantity of steroid (ng).

c The coefficient of correlation. 


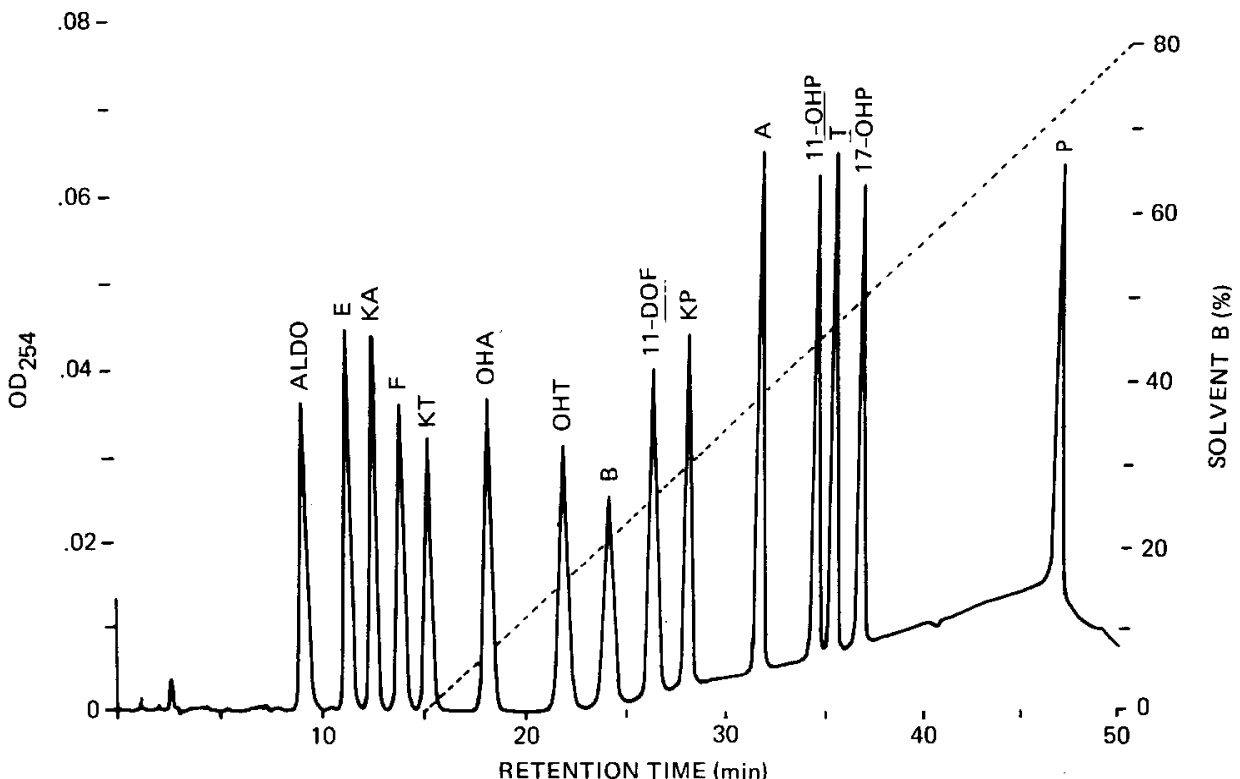

Fig. 1. The HPLC chromatogram of 15 authentic steroids ( $400 \mathrm{ng}$ each) on a ChemcoPak 7 ODS$\mathrm{H}$ column. The elution procedures were first with solvent $\mathrm{A}$ (water:methanol:acetonitrile:isopropanol 55:32:6.5:7.5, v/v) for $15 \mathrm{~min}$ and followed with a linear gradient elution for $35 \mathrm{~min}$ from 0 to $80 \%$ of solvent B (water:methanol:n-butanol 40:40:20, v/v). The flow rate was $1 \mathrm{ml} / \mathrm{min}$ and the chart speed was $0.6 \mathrm{~cm} / \mathrm{min}$. Attenuation was 0.1 absorbance unit full scale. Dashed line indicates the concentration of solvent $B$. For abbreviations see Table $I$.

dichloromethane phase was again evaporated to dryness. The residue was dissolved in an appropriate amount of methanol and ready for HPLC.

After bleeding, the fish was decapitated. The head kidneys and testes from several fishes were excised and pooled separately. They were homogenized twice in $10 \mathrm{vol}$ of ethanol $(w / v)$ by a PCU-2-110 Polytron (Kinematica $\mathrm{GmbH}$, Switzerland) or by a blender. The homogenized tissue was then extracted twice with $10 \mathrm{vol}(\mathrm{w} / \mathrm{v})$ of methanol:chloroform $(2: 1, \mathrm{v} / \mathrm{v})$. The organic phase was evaporated to dryness and then redissolved in an appropriate amount of methanol (any precipitate which appeared was removed by centrifugation). The methanol concentration was brought down to $70 \%$ by adding $1 \mathrm{M} \mathrm{CaCl}$. The methanol phase was kept at $-70^{\circ} \mathrm{C}$ for at least $4 \mathrm{~h}$ and the precipitate was removed by centrifugation. The methanol phase was evaporated to dryness and dissolved in $10 \mathrm{ml}$ dichloromethane. The further treatments (washings) were the same as those done for plasma sample.

In this study, $\left[{ }^{8} \mathrm{H}\right]$ cortisol $(200,000 \mathrm{cpm})$ and $\left[{ }^{14} \mathrm{C}\right]$ testosterone $(50,000 \mathrm{cpm})$ were added to plasma, head kidney, and testis prior to steroid extraction for correction of experimental loss. The $\left[{ }^{3} \mathrm{H}\right]$ cortisol was used for yield correction of cortisone and cortisol (moderately water soluble steroids) whereas $\left[{ }^{14} \mathrm{C}\right]$ testosterone for yield correction of other steroids (sparingly water-soluble steroids).

\section{RESULTS AND DISCUSSION}

As shown in Fig. 1, 15 authentic steroids (400 ng each), including corticosteroids, androgens, progestins, and their derivatives, can be completely separated within $50 \mathrm{~min}$ by the HPLC system developed in this study. This HPLC system is more convenient than those developed by O'Hare et al. (6) in which different classes of steroids should be resolved by different solvent systems.

The elution profile and calculated composition of the steroids in carp plasma are shown in Fig. 2 and Table III, respectively. Cortisol is the major and cortisone is the minor plasma corticosteroids. This result is in agreement with the observation that teleosts are cortisol secretor (8). The corticosteroid level of fish is elevated greatly by stress stimulation (9). It should be noted here that the level of plasma corticosteroids shown in Table III belongs to stressed carps. The details of the effect of stress stimulation on corticosteroid level of carp plasma will be described elsewhere. As shown in Fig. 2 and Table III, three an- 


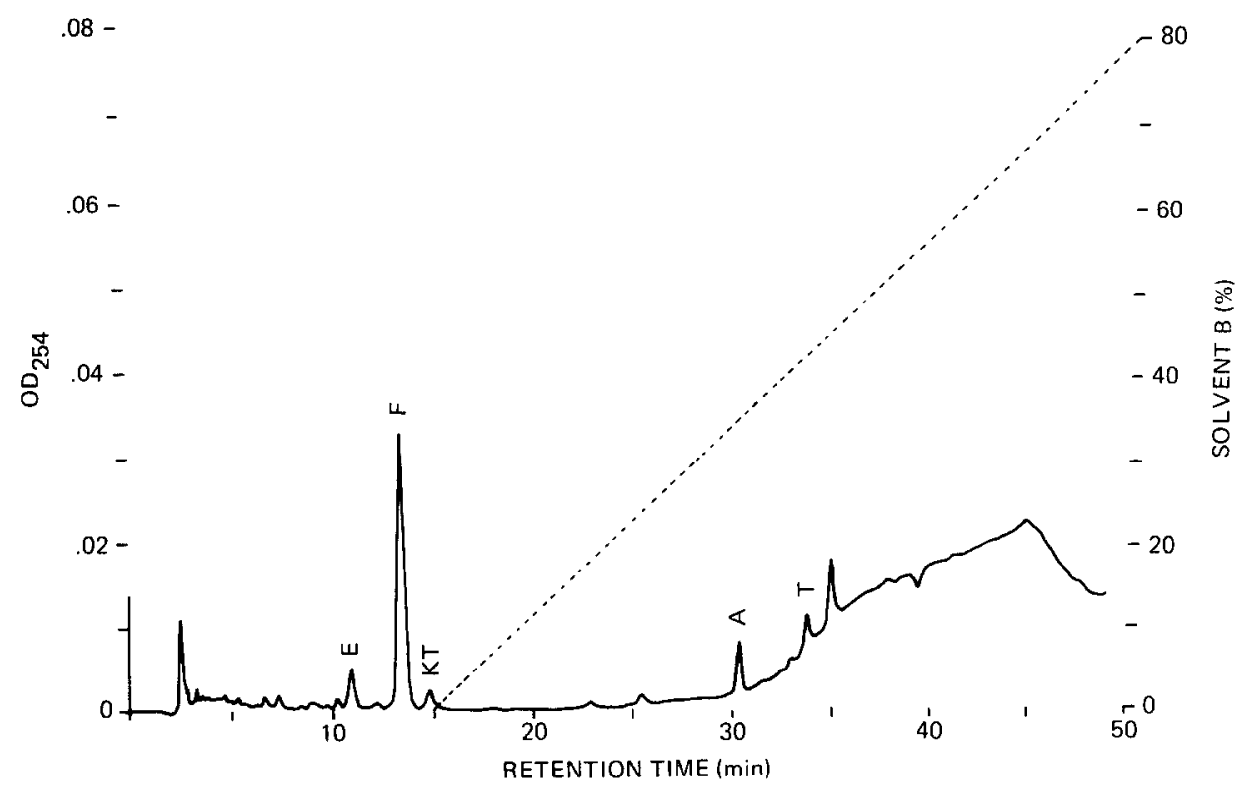

FIG. 2. The HPLC chromatogram of carp plasma. Extract from $8 \mathrm{ml}$ plasma was dissolved in 50 $\mu \mathrm{l}$ methanol and $20 \mu \mathrm{l}$ was injected for HPLC. Recovery of $\left[{ }^{3} \mathrm{H}\right]$ cortisol and $\left[{ }^{14} \mathrm{C}\right]$ testosterone were 79 and $86 \%$, respectively. The chromatography procedures and the other descriptions were the same as those presented in Fig. 1.

drogens, 11-ketotestosterone, androstenedione, and testosterone are also observed. The existence of 11-ketotestosterone is an unique feature in fish (10). The coexistence of 11-ketotestosterone and testosterone in plasma is also found in Oncorhynchus nerka (10), Salmo salar (11), and Thunnus thynnus (12).

The chromatogram and calculated results of the steroids of carp head kidney are shown in Fig. 3 and Table III, respectively. Cortisone and cortisol are the major corticosteroids. Although Fig. 3 indicates that in head kidney the amount of cortisol is higher than that of cortisone, the relative amount of cortisone and cortisol present in carp head kidney was found variable. From further studies it becomes clear that in certain individuals cortisone is predominant, in other individuals cortisol is predominant and in another individuals cortisone and cortisol are nearly equal. This individual variation may be probably due to different degree of stress and/or some

TABLE III

The Steroid Composition of Carp Plasma, Head Kidney, and Testis

\begin{tabular}{|c|c|c|c|c|c|c|c|c|c|c|c|c|c|}
\hline & \multicolumn{13}{|c|}{ Amount of steroid } \\
\hline & E & KA & $\mathbf{F}$ & KT & OHA & OHT & 11-DOF & $\mathbf{K P}$ & A & 11-OHP & $T$ & 17-OHP & $\mathbf{P}$ \\
\hline $\begin{array}{l}\text { Plasma } \\
\quad(\mathrm{ng} / \mathrm{ml})\end{array}$ & 18 & & 147 & 9 & & & & & 14 & & 11 & & \\
\hline $\begin{array}{l}\text { Head kidney } \\
\text { (ng/g) }\end{array}$ & 1298 & & 1430 & & & & 254 & & & 32 & & 942 & 254 \\
\hline $\begin{array}{l}\text { Testis } \\
\text { (ng/g) }\end{array}$ & 13 & 11 & 31 & 183 & 47 & 12 & & 6 & 3 & 3 & 31 & 14 & 219 \\
\hline
\end{tabular}




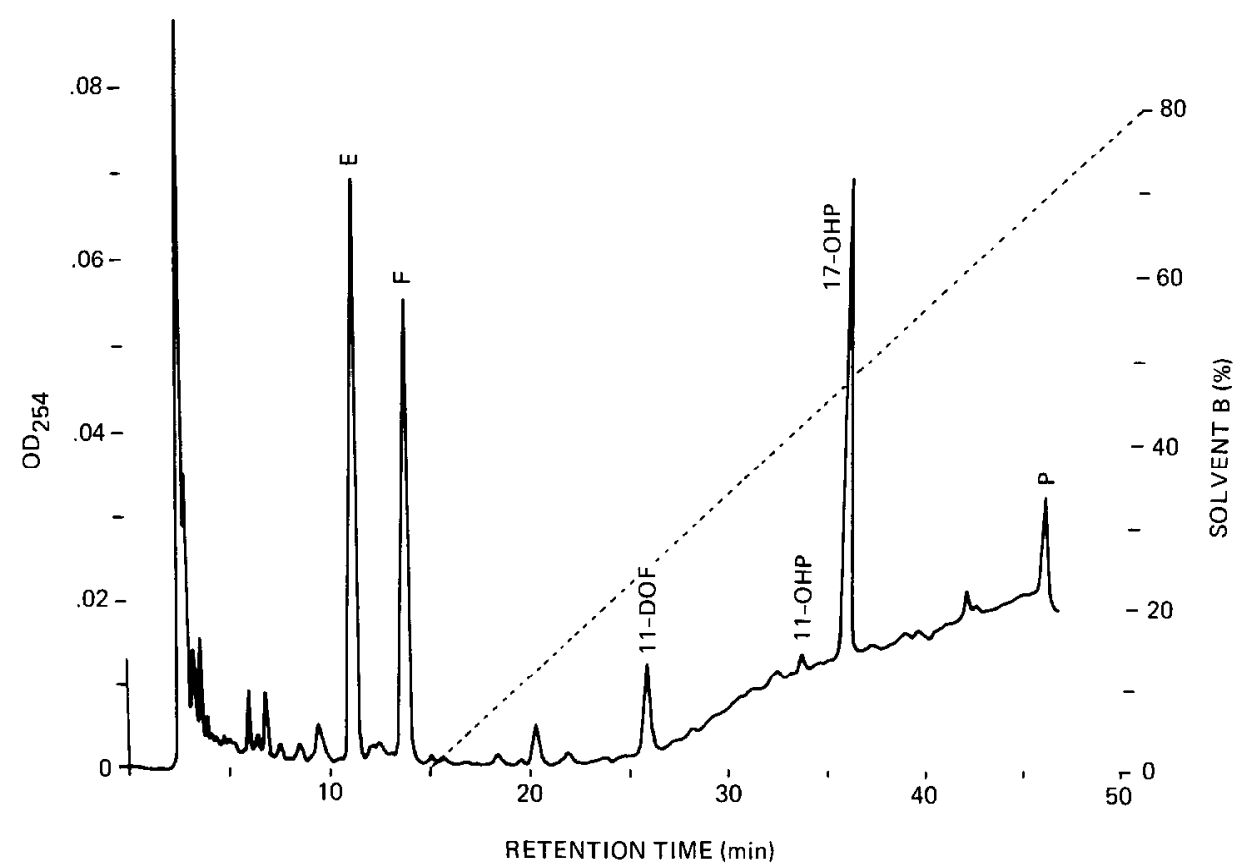

FIG. 3. The HPLC chromatogram of carp head kidney. Extract from $2.5 \mathrm{~g}$ head kidney was dissolved in $50 \mu \mathrm{l}$ methanol and $10 \mu \mathrm{l}$ was injected for HPLC. Recovery of $\left[{ }^{3} \mathrm{H}\right]$ cortisol and $\left[{ }^{14} \mathrm{C}\right]$ testosterone were 92 and $95 \%$, respectively. The chromatography and the other descriptions were the same as those presented in Fig. 1.

other unknown reasons. In addition to cortisone and cortisol, various intermediates of corticosteroid biosynthesis, progesterone, $17 \alpha$-hydroxyprogesterone, $11 \beta$-hydroxyprogesterone, and 11-deoxycortisol are also found in carp head kidney.

In the analysis of carp testis, only cortisone, cortisol, and 11-ketotestosterone are demonstrated by our HPLC system without prior cGTH treatment (data not shown). After cGTH treatment for $4 \mathrm{~h}$, a very complicate steroid profile appears in carp testis (Fig. 4 and Table III). It includes corticosteroids (cortisone, cortisol), androgens (androstenedione, testosterone), $11 \beta$ hydroxylated androgens (11 $\beta$-hydroxyandrostenedione, $11 \beta$-hydroxytestosterone), 11-ketoandrogens (adrenosterone, 11-ketotestosterone), and intermediates of corticosteroid and androgen biosynthesis (progesterone, $17 \alpha$-hydroxyprogesterone, $11 \beta$-hydroxyprogesterone, 11-ketoprogesterone). Such a complicate steroid profile is an unique feature in fish testis. The un- derlying reason that carp testis has a more complicate steroid profile than that of mammalian testis is due to that carp testis has $11 \beta$-hydroxylase which is lacking in normal mammalian testis.

The above experimental data indicate that the HPLC system newly developed in this study is highly effective in analyzing a very complicated steroid mixture present in fish. The sensitivity was in the nanogram range. Very recently, this procedure was employed in the studies of steroidogenesis in fish testis and head kidney in our laboratory. The results are very promising, and will be presented elsewhere. Because of the limitation of a detector used (uv detector at $254 \mathrm{~nm}$ ), steroids without $\alpha, \beta$ unsaturated 3-keto group were not investigated. It may be a major drawback of this method in analyzing steroid mixture at present. This disadvantage can be overcome by using far-uv detector with nonuv-absorbing solvent system or by precolumn treatment of steroid. 


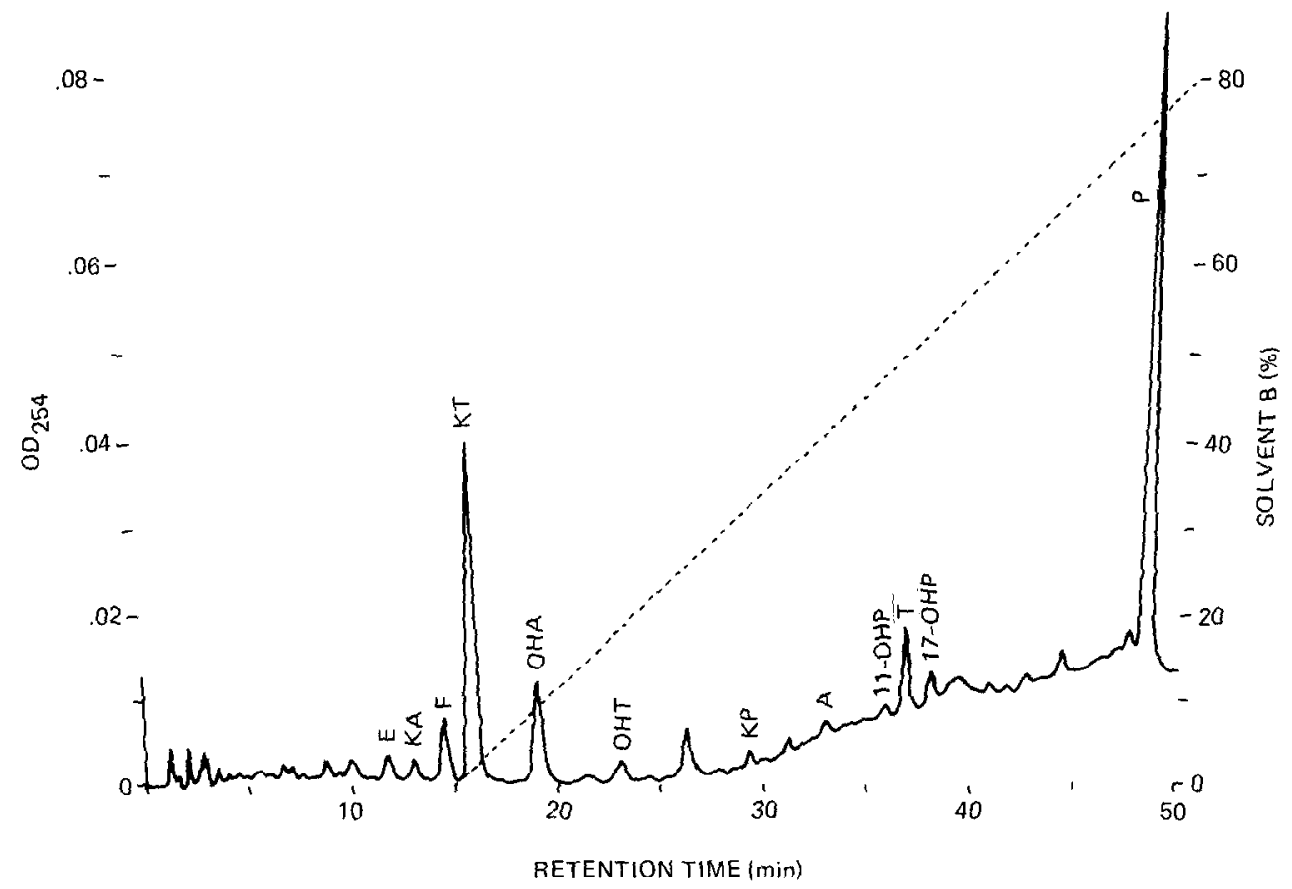

FIG. 4. The HPLC chromatogram of carp testis. Extract from $22.5 \mathrm{~g}$ testis (fish had treated with cGTH, $0.5 \mu \mathrm{g} / \mathrm{g}$ body weight, for $4 \mathrm{~h}$ ) was dissolved in $50 \mu 1$ methanol and $20 \mu \mathrm{l}$ was injected for HPLC. Recovery of $\left[{ }^{8} \mathrm{H}\right]$ cortisol and $\left[{ }^{14} \mathrm{C}\right]$ testosterone were 27 and $36 \%$, respectively. The chromatography and the other descriptions were the same as those presented in Fig. 1.

\section{ACKNOWLEDGMENT}

This work was supported by Grant NSC 70-0203B001-04 from the National Scjence Council, Republic of China.

\section{REFERENCES}

1. DoMINGUEz, O. V. (1961) J. Clin. Endocrinol Metab. 21, 663-674.

2. Bloch, E., AND CoHEN, A. E. (1960) J. Nat. Cancer Invest. 24, 97-107.

3. ARA, R., AND TAMAOKI, B. I. (1967) Can. J. Biochem. 45, 1191-1195.

4. IDLER, D. R., AND MCNAB, H. C. (1967) Can. J. Biochem. 45, 581-589.

5. VAN Den HuRK, R., ANd Lambert, J. G. D. (1977) Comp. Biochem. Physiol. B 56, 117-118.
6. O'HARe, M. J., Nice, E. C., Megee-Brown, R., AND Bullman, H. (1976) J. Chromatogr. 125, $357-367$.

7. HuANG, F. L., AND Chang, Y. S. (1980) Nat. Sci. Connc. Repub. China Proc. 4, 392-400.

8. SANDOR, T., AND MEHDI, A. Z. (1979) in Hormones and Evolution (E. J. W. Barrington, ed.), Vol. 1, pp. 1-72, Academic Press, New York.

9. LEACH, G. J., AND TAYLOR, M. H. (1980) Gen. Comp. Endocrinol 42, 219-227.

10. IDLER, D. R., SCHMIDT, P. J., AND RONALD, A. P. (1960) Can J. Physiol. 38, 1053-1057.

11. IDLER, D. R., HoRnE, D. A., AND SANGalang, G. B. (1971) Gen. Comp. Endocrinol 16, 257267.

12. Sangalang, G. B., Freeman, H. C., and FlemMING, R. G. (1978) Gen. Comp. Endocrinol. 36, 187-193. 